\title{
Data is as data does
}

\author{
Robert J. Cerfolio, MD, MBA, FACS, FCCP
}

\author{
From the Department of Cardiothoracic Surgery, New York University Langone Health, New York, NY. \\ Disclosures: Dr Cerfolio is a teacher for Intuitive, C-SATS, Bovie, Ethicon, Covidien, Community Health Ser- \\ vices, Bard, ConMed, and Myriad Genetics. \\ Received for publication Sept 12, 2018; accepted for publication Sept 13, 2018; available ahead of print Oct 25, \\ 2018. \\ Address for reprints: Robert J. Cerfolio, MD, MBA, FACS, FCCP, Department of Cardiothoracic Surgery, New \\ York University Langone Health, 550 1st Ave, 15th Floor, New York, NY 10016 (E-mail: Robert.Cerfolio@ \\ nyumc.org). \\ J Thorac Cardiovasc Surg 2019;157:387 \\ $0022-5223 / \$ 36.00$ \\ Copyright (c) 2018 by The American Association for Thoracic Surgery \\ https://doi.org/10.1016/j.jtcvs.2018.09.045
}

Jiwnani and colleagues ${ }^{1}$ present the type of study that more of us need to do more often-a prospective, randomized, patient-blinded trial. The authors have offered a different conclusion when compared with the 3 studies that we have on a similar topic ${ }^{2-4}$ (that the authors kindly reference in their article) and it is different from the studies from Bayram and colleagues in $2011^{5}$ and Allama in $2010 .^{6}$ All of these trials confirmed our initial finding that sparing the intercostal muscle and its nerve decreases the pain of thoracotomy.

Perhaps the most important part of the study cuts to the very heart of evidence-based medicine. It is what we all want to try to optimize in our daily lives: The use of objective data to make decisions. Yet, how can we can make sense of conflicting data? The answer lies in our ability to read each study and focus on the methods, the quality of the data, the statistics, and understand the strengths and weakness that are inherent to every study.

We can and should list some of the problems in this current study: there were only 45 people in each arm (was it underpowered?), there were multiple surgeons (does this affect the results?), $24 \%$ of patients in 1 arm and $18 \%$ in the other had broken ribs (does this mitigate the pain reduction of sparing the intercostal nerve?), and the authors scored pain only at 4 time periods - on postoperative day 1,2 , and 3 and at 6 months and did not tell us when they obtained the inpatient data relative to each patient's morphine injections (is this sufficient quantity and quality to detect a difference if it existed?).

Furthermore, 3 of the 4 pain data points in Figure 6 of the article $^{1}$ show the group that underwent the intercostal muscle flap had less pain. Table $3^{1}$ shows that patients who got the muscle flap did better in 6 of the 7 categories (ie, less pulmonary complications, shorter stay in the intensive

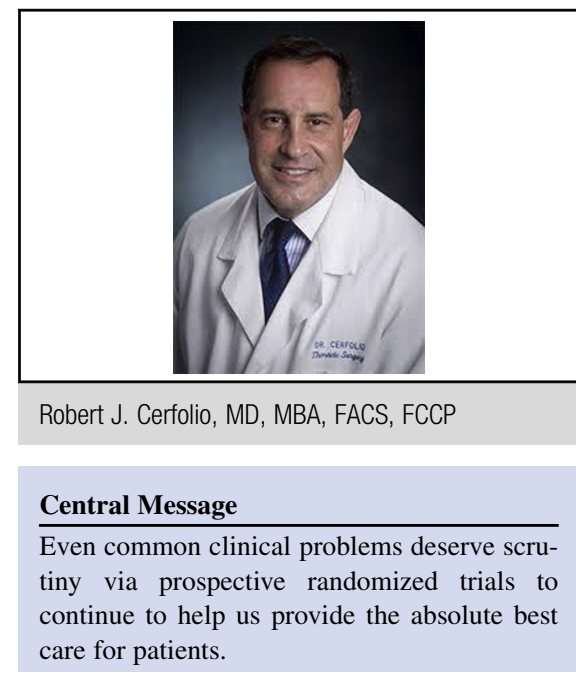

See Article page 380.

care unit, fewer major wound infections, had a shorter median length of stay, fewer readmissions, and fewer postoperative deaths). None achieved statistical significance but there were only 45 patients in each arm.

In the same vein, we can punch just as many holes in the 3 studies we performed, ${ }^{2-4}$ perhaps more. I congratulate the authors on their work and encourage them to continue to ask critical questions and study common clinical problems. We should continue to perform prospective randomize blinded studies. Because at the end of the day, what matters most is our ability to offer our patients the absolute best care we can, because the best care is the only care that our patients deserve.

\section{References}

1. Jiwnani S, Ranganathan P, Patil V, Agarwal V, Karimundackal G, Pramesh CS Pain after posterolateral versus nerve-sparing thoracotomy: a randomized trial. $J$ Thorac Cardiovasc Surg. 2019;157:380-6.

2. Cerfolio RJ, Price TN, Bryant AS, Sale Bass C, Bartolucci AA. Intracostal sutures decrease the pain of thoracotomy. Ann Thorac Surg. 2003;76:407-11.

3. Cerfolio RJ, Bryant AS, Patel B, Bartolucci AA. Intercostal muscle flap reduces the pain of thoracotomy: a prospective randomized trial. J Thorac Cardiovasc Surg. 2005;130:987-93

4. Cerfolio RJ, Bryant AS, Maniscalco LM. A nondivided intercostal muscle flap further reduces pain of thoracotomy: a prospective randomized trial. Ann Thorac Surg. 2008;85:1901-6.

5. Bayram AS, Ozcan M, Kaya FN, Gebitekin C. Rib approximation without intercostal nerve compression reduces post-thoracotomy pain: a prospective randomized study. Eur J Cardiothorac Surg. 2011;39:570-4.

6. Allama AM. Intercostal muscle flap for decreasing pain after thoracotomy: a prospective randomized trial. Ann Thorac Surg. 2010;89:195-9. 